\title{
Perbedaaan Pengaruh Pembelajaran Mata Pelajaran Kimia Model Problem Based Learning (PBL) Dan Cooperative Learning Tipe Think Pair Share (TPS) terhadap Prestasi Belajar Siswa Ditinjau dari Aktivitas Belajar Siswa SMA Negeri di Grobogan
}

\author{
Ria Rahmawati13, Leo Agung S14, Nunuk Suryani15 \\ ria.rahmawati68@gmail.com
}

\begin{abstract}
Abstrak: This study aimed to: (1) To determine the effect of differences in chemistry learning PBL models and models of SMT for high school student achievement in Grobogan. (2) To find out which is better student achievement with learning activity is high or low high school learning activities in Grobogan. (3) To understand the interaction model of learning by students' learning activities to the achievement of high school students studying chemistry in Grobogan. The research was conducted at several high schools in Grobogan including; SMA $N$ 1Gabus, SMA N 1 Kradenan, SMA N 1 Wirosari. The model used in this research is experiment with $2 X 2$ factorial design. The study design using experimental. The results showed that. (1) Differences Influence Model Model PBL with TPS on Learning Achievement in Chemistry. Results of Two-Way ANOVA analysis showed a significant difference in learning achievement chemical groups using PBL and group learning model TPS, with a value of $F=5.432, p<0.05$ where student achievement in the subjects of Chemistry with PBL models better than the student who uses a model TPS. (2) Differences in Effects of High learning activities with learning activities Low toward achievement of learning chemistry. Results of Two-Way ANOVA analysis showed a significant difference in learning achievement Chemistry group of students with high learning activities and groups of students with low learning activity, with the value of $F=8.218, p<0.05$ where learning achievement in the subjects of Chemistry students who have high learning activity is better than the students who have low learning activities . (3) Interaction Effect Model of learning and learning activities in relation to the achievement of learning chemistry. The result of the calculation of the Two-Way ANOVA analysis finds that there are interactions between the learning model with learning activities to learning achievement Chemistry with a value of $F=$ $4.020, p<0.05$ where the average value of learning achievement chemical group PBL models with high learning activity has the highest value of the interpretation of study with a mean of 84.41 while PBL model group with low learning activity have the lowest average value for 74.13 .
\end{abstract}

Keywords: Learning Model Problem Based Learning, Think Pair Share, Chemistry learning achivement, Learning activities.

\footnotetext{
${ }^{13}$ Alumni Magister Teknologi Pendidikan Universitas Sebelas Maret Surakarta

14 Dosen Universitas Sebelas Maret Surakarta

15 Dosen Universitas Sebelas Maret Surakarta 


\section{PENDAHULUAN}

endidikan merupakan suatu usaha yang dilakukan untuk mengubah tingkah laku manusia baik secara individu maupun kelompok dalam upaya mendewasakan manusia melalui pengajaran dan pelatihan. Pendidikan merupakan proses pembelajaran yang dapat meningkatkan kualitas sumber daya manusia dengan mengembangkan potensi dirinya serta membangun kepribadian yang baik dalam dirinya sehingga menghasilkan sumber daya manusia yang berkualitas, bermutu dan bermartabat.

Sebagai proses pembudayaan dan pemberdayaan pada siswa yang berlangsung sepanjang hayat. Salah satu proses menerapkan pendidikan adalah dengan melakukan kegiatan pembelajaran. Proses pembelajaran yang berlangsung harus interaktif, inspiratif, menyenangkan, menantang dan memotivasi siswa untuk berpartisipasi aktif, serta memberikan ruang lingkup yang cukup bagi siswa (BSNP, 2007). Pada dasarnya semua mata pelajaran memerlukan proses tersebut agar tercapainya tujuan pembelajaran. Salah satu mata pelajaran tersebut adalah mata pelajaran kimia. Kimia merupakan mata pelajaran yang harus dilaksanakan dengan pembelajaran yang dapat melibatkan keterampilan dan penalaran siswa, sehingga siswa memperoleh pengetahuan secara utuh melihat kimia sebagai proses (kerja ilmiah) dan produk (fakta-fakta, konsep-konsep, atau prinsip-prinsip) (BSNP, 2007).

Berdasarkan observasi awal yang dilakukan di SMA Negeri di Grobogan diperoleh sebagian besar siswa masih merasa kesulitan dalam belajar kimia, siswa lebih cenderung mempelajari kimia sebagai produk, menghafal konsep, teori dan hukum. Proses pembelajaran masih berpusat pada guru (teacher centered). Guru merupakan sumber informasi utama bagi siswa. Guru merupakan subjek aktif yang tugasnya memberikan informasi dan ilmu pengetahuan, sedangkan siswa hanya pasif karena tugas mereka hanya menampung apa saja yang diberikan guru ke dalam pikirannya. Akibatnya, komunikasi hanya berlangsung satu arah saja yaitu hanya dari guru ke siswa. Siswa kurang berperan aktif dalam proses pembelajaran dan aktivitas siswa selama pembelajaran kurang terlihat. Pembelajaran kimia yang berlangsug belum menggunkan model/metode yang kurang bervariasi mengakibatkan proses pembelajaran yang terjadi cenderung monoton mengakibatkan siswa mengalami kejenuhan kurang bersemangat dalam mengikuti pembelajaran.

Mengingat beberapa materi kimia yang bersifat abstrak, sehingga siswa belajar kimia hanya dengan membayangkan. Kurangnya pemberian pengalaman langsung kepada siswa dalam proses pembelajaran meliputi mengumpulkan informasi dari berbagai sumber, memecahkan masalah atau membuktikan teori sehingga siswa merasa kesulitan dalam menyerap pengetahuan materi kimia.

Pembelajaran yang telah dilaksanakan guru belum melakukan variasi model/metode pembelajaran yang mengikutsertakan siswa untuk berpartisipasi aktif dalam proses pembelajaran. Siswa juga belum diberi kesempatan untuk berpartisipasi membangun pengetahuannya sendiri melalui mengumpulkan informasi atau penyelidikan secara individu atau kelompok. Selama proses pembelajaran berlangsung para siswa hanya mendengarkan informasi dari guru mengakibatkan interaksi antara guru dengan siswa dan antar siswa tidak berlangsung sehingga aktivitas belajar siswa belum tergali dan prestasi belajar kimia siswa belum tercapai dengan maksimal.

Adanya berbagai permasalahan di atas, perlu adanya perubahan paradigma dalam menelaah proses belajar siswa dan interaksi siswa dengan guru. Salah satu perubahan paradigma tersebut adalah orientasi pembelajaran yang semula berpusat pada guru (teacher centered) beralih berpusat pada siswa (student centered).

Satu inovasi yang menarik untuk mengubah paradigma tersebut adalah ditemukan dan diterapkannya model pembelajaran yang inovatif dan konstruktif atau lebih tepat dalam mengembangkan dan menggali pengetahuan siswa secara konkret dan mandiri serta dapat 
meningkatkan aktivitas siswa dalam pembelajaran yang akhirnya dapat meningkatkan kemampuan siswa baik kemampuan kognitif, psikomotor dan afektifnya. Siswa dituntut aktif selama pembelajaran berlangsung dan guru berperan sebagai fasilitator, sehingga siswa dengan sendirinya dapat membangun pengetahuannya secara aktif. siswa dapat meningkatkan kualitas dan aktivitas belajarnya karena semakin luas kesempatan untuk mencari pengetahuan sendiri dengan pengalamannya sendiri, bertanya dan berdiskusi dengan guru maupun siswa lainnya. Proses pembelajaran tersebut merupakan salah satu tujuan pembelajaran mata pelajaran kimia.

Sehubungan dengan hal ini, para siswa membutuhkan motivasi yang lebih agar memiliki semangat yang tinggi dalam belajar. Untuk itu guru perlu menerapkan model-model pembelajaran yang inovatif untuk melaksanakan kegiatan pembelajaran sehingga dapat mengetahui model-model pembelajaran yang paling efektif untuk digunakan dalam pembelajaran kimia. Model pembelajaran yang digunakan juga dapat membentuk rencana pembelajaran jangka panjang, merancang bahan-bahan pembelajaran, dan membimbing pembelajaran di kelas (Joyce \& Weil, 1980).

Dua model pembelajaran inovatif yang diduga dapat menjadi alternatif mengatasi permasalahanpermasalahan pembelajaran yang telah disebutkan di atas yaitu model pembelajaran Problem Based Learning (PBL) dan model pembelajaran kooperatif.

Model pembelajaran PBL atau disebut juga model pembelajaran berbasis masalah. Model PBL adalah model pembelajaran yang memfasilitasi siswa untuk memecahkan masalah yang nyata dikehidupan sehari-hari (Anitah, 2009). PBL merupakan pembelajaran berbasis penemuan yang mana siswa diberikan masalah nyata untuk diselidiki secara mendalam dari apa yang mereka butuhkan dan apa yang mereka tahu (Akcay, 2009). Pengaitan materi dengan kehidupan sehari-hari dapat membuat siswa merasa dalam belajar kimia mempelajari hal-hal yang riil ada disekitarnya, bukan melainkan hal yang berbentuk abstrak sehingga siswa terdorong untuk belajar kimia dan menganggap belajar kimia merupakan hal yang nyata dan menyenangkan. Dorongan rasa suka terhadap pelajaran dapat membuat siswa menjadi tertarik untuk mempelajarinya mengakibatkan interaksi di kelas akan terjalin antara guru dengan siswa, maupun siswa dengan siswa. Adanya interaksi yang sering berlangsung menunjukkan aktivitas siswa di kelas akan semakin tinggi. Melalui model PBL ini siswa dituntut berperan aktif dalam proses pembelajaran dikarenakan siswa harus menyelesaikan tugas dari guru untuk memecahkan suatu masalah secara mandiri ataupun kelompok melalui studi kasus atau penyelidikan. Masalah yang diberikan guru tentunya yang memberikan tantangan dan motivasi kepada siswa untuk menyelidiki lebih mendalam suatu konsep (Duch, Allen \& White, 2002). Pembelajaran kimia banyak melibatkan studi kasus seperti model PBL siswa akan diberikan masalah yang harus diselesaikan langsung oleh siswa mengakibatkan siswa terdorong mengumpulkan informasi dari berbagai sumber atau penyelidikan dengan mengaitkan pengetahuan yang sudah diketahui tentang halhal kimia dengan pengetahuan yang baru bagi siswa dan fokus pembelajaran yang berlangsung dari berpusat pada guru menjadi berpusat pad siswa (Kelly \& Finlayson, 2007; Akcay, 2009). Model PBL berdasar pada teori pembelajaran konstruktivis yang menyatakan melalui penyelidikan di lingkungan sekitar dan membangun pengetahuannya secara mandiri dari pengetahuan yang sudah ada dengan pengetahuan baru (Arends, 1997). Keterkaitan pengetahuan yang lama tersimpan di otak dengan pengetahuan baru dapat membuat pembelajaran siswa menjadi lebih bermakna (Dahar, 1996). Semakin bermakna pengetahuan yang diperoleh oleh siswa semakin mudah siswa memahami materi kimia. Pada pembelajaran model PBL memberikan kesempatan kepada siswa untuk mengalami pengalaman langsung selama belajar kimia, seperti menggali informasi tentang materi kimia, melakukan penyelidikan dengan melakukan praktikum, mengolah data hasil praktikum, menarik kesimpulan dengan materi yang dipelajari sehingga siswa dapat membangun sendiri pengetahuannya. Rangkaian kegiatan-kegiatan tersebut dapat mendorong pembelajaran yang multi interaksi, sehingga dapat meningkatkan aktivitas siswa selama proses pembelajaran. Meningkatnya aktivitas siswa maka semakin banyak pengetahuan yang diperoleh untuk membekali siswa dalam belajar kimia agar memperoleh prestasi yang ingin dicapai. 
Selain itu, model pembelajaran lain dengan model kooperatif. Pembelajaran dengan model ini siswa dilatih untuk bekerja sama atau bergotong royong dengan teman-temannya untuk menyelesaikan tugas yang diberikan oleh guru. Menurut Doymus (2008) Model pembelajaran kooperatif merupakan model pembelajaran yang membantu siswa untuk belajar satu sama lain dengan membuat kelompok kecil dalam materi tertentu, menumbuhkan kepercayaan diri, mengembangkan skill komunikasi dan dapat meningkatkan kemampuan menyelesaikan masalah, berfikir kritis, serta siswa aktif selama proses pembelajaran. Model kooperatif menjadi salah satu pendekatan yang mengubah fokus pembelajaran yang didominasi guru menuju terpusat pada siswa (Oludipe \& Awakoy, 2010). Salah satu model pembelajaran kooperatif yang menarik bagi siswa untuk belajar adalah model pembelajaran kooperatif tipe Think Pair Share (TPS). Model pembelajaran kooperatif tipe TPS merupakan sebuah model pembelajaran yang bertujuan untuk mengajarkan siswa agar lebih mandiri dalam menyelesaikan tugas secara berkelompok dan dapat membangkitkan rasa percaya diri siswa (slavin, 1995). Pengetahuan yang diperoleh dengan pemikirannya sendiri membuat siswa lebih mudah dalam belajar. Pembelajaran kooperatif tipe TPS siswa melalui tiga tahapan yaitu waktu untuk berfikir, berbagi dengan pasangan, dan berbagi dengan pasangan lainnya (Bamiro, 2015). Tiga tahapan ini memberikan waktu kepada siswa untuk mengolah pengetahuan yang diperoleh untuk dibagi dengan teman pasangannya untuk lebih memahami materi yang diperoleh. Siswa menjadi lebih mudah mengolah pengetahuan yang diperoleh sesuai dengan apa yang dipemikirannya dan dipahaminya sehingga membuat siswa mudah dalam belajar kimia. Siswa diberi kesempatan untuk mencari informasi-informasi dari berbagai sumber untuk menyelesaikan tugasnya sehingga tercipta lingkungan belajar (Koc, Seda, \& Bilge, 2013). Keadaan tersebut membuat pengetahuan akan mudah diterima oleh siswa karena siswa menyelesaikan tugas dengan pemikirannya sendiri melalui diskusi dengan siswa lain. Proses pembelajaran tersebut dapat mengakibatkan aktivitas belajar siswa meningkat karena siswa lebih berani untuk mengeksplor pengetahuannya dengan temannya sendiri (Kagan \& Kagan, 2009).. Sugiato \& Sumarsono (2014) mengungkapkan bahwa model koperatif tipe TPS membuat siswa lebih aktif selama proses pembelajaran dengan berdiskusi bersama teman-temannya. Pembelajaran kooperatif yang melibatkan pembelajaran antara siswa satu dengan siswa lainya untuk kerja sama dengan menggabungkan banyak pemikiran akan memudakan dan menarik siswa dalam belajar kimia karena siswa merasa lebih mudah menerima penjelasan melalui teman sebayanya kemudian jika ada materi yang belum bisa dipahami siswa secara bersama-sama untuk menanyakan kepada guru. Kegitan ini dapat mengatasi kesulitan siswa dalam belajar kimia. Aktivitas-aktivitas tersebut dapat membantu siswa dalam belajar sehingga dapat meningkatkan prestasi belajar kimia. Selain itu, model TPS ini juga mengajarkan siswa untuk bisa menerima perbedaan pendapat dan bekerja sama dengan orang lain. Model pembelajaran TPS dapat menjadi motivasi bagi siswa dalam belajar sehingga dapat meningkatkan aktivitas dan prestasi belajarnya.

Proses pembelajaran pada hakekatnya untuk mengembangkan aktivitas melalui berbagai interaksi dan pengalaman belajar. Menurut Wijaya \& Dwigatama (2010) aktivitas belajar merupakan keterlibatan intelektual dan emosional siswa dalam kegiatan belajar mengajar, asimilasi, dan akomodasi kognitif. Sardiman (2008) menyatakan bahwa siswa dikatakan belajar setelah melakukan aktivitas. Aktivitas dapat berupa aktivitas fisik maupun psikis. Siswa melakukan aktivitas selama pembelajaran memperlihatkan siswa merupakan manusia belajar aktif yang selalu ingin tahu (Dimyati \& Mudjiono, 2009). Aktivitas belajar siswa antara lain: (a) Visual activities, (b) Oral activities, (c) Listening activities, (d) Writing activities, seperti: (c) Drawing activities, (d) Motor activities, (e) Mental activities, (f) Emosional activities, (Paul B. Diedrich dalam Sardiman, 2010).

Tujuan penelitian iniuntuk mengetahui (1) perbedaan pengaruh pembelajaran kimia model Problem Based Learning dan model kooperatif tipe Think Pair Share terhadap Prestasi belajar siswa kelas X SMA Negeri di Grobogan; (2) perbedaan pengaruh aktivitas belajar tinggi dengan aktivitas belajar rendah terhadap prestasi belajar kimia siswa kelas X SMA Negeridi Grobogan; (3) interaksi 
pengaruh model pembelajaran dan aktivitas belajar siswa terhadap prestasi belajar kimia siswa kelas $\mathrm{X}$ SMA Negeri di Grobogan.

Penelitian ini dilaksanakan di SMA Negeri 1 Wirosari dan SMA Negeri 1 Gabus. Penelitian dilakukan dengan metode eksperimen dengan rancangan faktorial 2X2 (Sugiyono, 2010). Teknik pengambilan sampel adalah cluster random sampling. Populasi dalam penelitian adalah siswa kelas $X$ SMA Negeri di Grobogan dan sampel yang digunakan dalam penelitian ini adalah mengambil dua kelas, yaitu untuk perlakuan penelitian dengan model pembelajaran PBL di kelas X IPA SMA N 1 Wirosari dan model kooperatif tipe TPS di kelas X IPA Gabus. Teknik pengumpulan data yang digunakan dalam penelitian ini meliputi tes prestasi dan angket aktivitas belajar. Tes digunakan untuk memperoleh data hasil belajar sebanyak 37 butir soal dan angket sebanyak 24 item. Kedua instrumen tersebut sudah diuji dan layak untuk digunakan untuk penelitian. Tes hasil belajar secara konstruk diuji validitas tiap itemnya dengan bantuan micro CAT dengan iteman sedangkan angket aktivitas belajar diuji validitasnya tiap item dengan product moment correlation dan diuji dengan cronbachs alpha. Data penelitian dianalisis dengan tahap-tahap sebagai berikut: 1) uji prasyarat analisis, yang terdiri atas uji normalitas dan uji homogenitas variansi, 2) Uji hipotesis penelitian ini menggunakan uji Two-Way Anova dan uji lanjut scheffe test.

\section{HASIL PENELITIAN DAN PEMBAHASAN}

Sesuai dengan analisis Two-Way Anova berarti dalam penelitian ini akan menunjukkan pebedaan pengaruh antara model pembelajaran, aktivitas belajar, dan interaksi model pembelajran dengan akivitas belajar. penelitian ini juga mengunakan desain faktorial $2 \times 2$ yang menjadikan sampel terbagi menjadi empat kelompok kombinasi dari kedua faktor tersebut. deskriptif nilai-nilai dari maingmasing kelompok ditunjukkan dalam tabel 1.

Prestasi belajar kelompok model PBL menunjukkan rata-rata sebesar 81,37 dan kelompok model kooperatif tipe TPS sebesar 74,89. Hasil ini menunjukkan bahwa kelompok model PBL mencapai prestasi lebih baik dari pada kelompok model TPS.

Tabel 1. Deskriptif Prestasi Belajar siswa

\begin{tabular}{|c|c|c|c|c|c|}
\hline \multirow{2}{*}{$A$} & & \multirow[t]{2}{*}{ Sumber Statistik } & \multicolumn{2}{|c|}{ Aktivitas belajar } & \multirow[t]{2}{*}{ Total } \\
\hline & & & $\begin{array}{c}\text { Tinggi } \\
\left(B_{1}\right)\end{array}$ & $\begin{array}{r}\text { Rendah } \\
\left(\mathrm{B}_{2}\right)\end{array}$ & \\
\hline \multirow{15}{*}{ 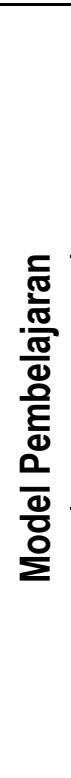 } & \multirow{5}{*}{$\begin{array}{l}\text { PBL } \\
\left(A_{1}\right)\end{array}$} & $\mathrm{N}$ & 26 & 12 & 38 \\
\hline & & Minimum & 67,57 & 62,16 & 62,16 \\
\hline & & Maksimum & 94,59 & 83,78 & 94,59 \\
\hline & & Rerata & 84,41 & 74,78 & 81,37 \\
\hline & & SD & 7,73 & 7,04 & 8,70 \\
\hline & \multirow{5}{*}{$\begin{array}{c}\text { TPS } \\
\left(A_{2}\right)\end{array}$} & $\mathrm{N}$ & 17 & 21 & 38 \\
\hline & & Minimum & 62,16 & 54,05 & 54,05 \\
\hline & & Maksimum & 91,89 & 89,19 & 91,89 \\
\hline & & Rerata & 75,83 & 74,13 & 74,89 \\
\hline & & SD & 9,32 & 9,77 & 8,88 \\
\hline & \multirow{5}{*}{ Total } & $\mathrm{N}$ & 43 & 33 & \\
\hline & & Minimum & 62,16 & 54,05 & \\
\hline & & Maksimum & 94,59 & 89,19 & \\
\hline & & Rerata & 81,02 & 74,37 & \\
\hline & & SD & 8,78 & 7,04 & \\
\hline
\end{tabular}


Rata-rata nilai siswa dikelompok aktivitas belajar tinggi sebesar 81,02, sedangkan dikelompok aktivitas elajar rendah sebesar 74,37 . Hal ini menunjukan bahwa siswa dengan aktivitas belajar yang tinggi mencapai prestasi belajar yang lebih baik dibandingkan dengan aktivitas belajarnya yang rendah.

Terdapat empat kelompok dalam penelitian ini diantanranya kelompok model PBL dengan aktivitas belajar tinggi $\left(A_{1} B_{1}\right)$, model PBL dengan aktivitas belajar rendah $\left(A_{1} B_{2}\right)$, model TPS dengan aktivitas belajar tinggi $\left(A_{2} B_{1}\right)$, dan model TPS dengan aktivitas belajar rendah $\left(A_{2} B_{2}\right)$. Hasil penelitian menunjukkan bahwa model PBL dengan aktivitas belajar tinggi mendapatkan nilai rerata tertinggi sebesar 84,71 .

Hasil pengujian statistik menggunakan analisis Two Way Anova juga menunjukkan terdapat perbedaan yang signifikan hasil antara prestasi dengan ketiga sumber variasi. Hasil pengujian hipotesis dapat dilihatm pada Tabel 2.

Tabel 2. Uji Hipotes Two Way Anova

\begin{tabular}{ccccccc}
\hline Sumber & JK & Dk & RK & F & P & ket \\
\hline Model (A) & 372,185 & 1 & 372,185 & 5,432 & 0,023 & Sig \\
\hline Aktivitas Belajar (B) & 563,038 & 1 & 563,038 & 8,218 & 0,005 & Sig \\
\hline Interaksi AB & 275,424 & 1 & 275,424 & 4,020 & 0,049 & Sig \\
\hline Galat & 4933,006 & 72 & & & & \\
\hline Total & 470436,752 & 76 & & & & \\
\hline
\end{tabular}

Pengujian hipotesis dapat terlihat diperoleh tiga data yang pertama, bahwa terdapat perbedaan pengaruh antar model yang ditunjukkan dari hasil perhitungan diperoleh nilai $p \quad 0,023<0,05$. Kedua, terdapat perbedaan pengaruh antar aktivitas dengan nilai p $0,005<0,05$, ketiga, terdapat interaksi antar model pembelajara dan aktivitas belajar diperoleh nilai $p$ sebesar 0,049<0,05.

Hasil pengujian hipotesis yang menunjukkan terdapat interaksi antara model pembelajaran dan aktivitas belajar siswa maka pengujian dilanjutkan dengan uji lanjut anava (Sceffe) diperoleh model PBL dengan aktivitas belajar tinggi terdapat perbedaan yang signifikan dengan model PBL dan aktivitas belajar rendah, model TPS dan aktivitas belajar tinggi, serta model TPS dan aktivitas belajar rendah.

Dengan demikian dapat disimpulkan bahwa pembelajaran menggunakan model PBL dengan aktivitas belajar tinggi memberikan pengaruh yang lebih baik terhadap prestasi belajar kimia. Terlihat dari rata-rata nilai prestasi belajar siswa dikelompok model PBL dan aktivitas belajar tinggi juga menunjukkan rata-rata yang palig tinggi dari pada kelompok lain.

Melalui model PBL siswa dapat berperan aktif dalam proses pembelajaran dikarenakan siswa harus menyelesaikan tugas dari guru untuk memecahkan suatu masalah secara mandiri ataupun kelompok melalui studi kasus atau penyelidikan.

Sejalan dengan penelitian Suharta \& Luthan (2013) bahwa menggunakan model PBL membuat siswa melakukan aktivitas selama proses pebelajaran berlangsung sehingga pembelajaran berpusat pada siswa dan kemampuan kognitif, afektif, dan psikomotorik siswa tergali yang mengarahkan siswa semakin kreatif dan demokratif. Pembelajaran model PBL melibatkan tiga teori pembelajaran yaitu teori kontekstal, metakognisi, dan konsruktivisme (Gijselaers dalam Graaff \& Kolmos, 2003). Model ini akan menghubungkan pembelajaran dengan masalah di lingkungan sekitar sehingga lebih mudah untuk 
mempelajarinya karena disangkutkan dengan masalah nyata. Pemanfaatan lingkungan sekitar dapat meningkatkan motivasi, ketertarikan, dan efisiensi dalam belajar untuk memaksimalkan aktivitasnya selam proses pembelajaran berlangsung (Tsankov, 2012).

Hasil penelitian juga menunjukkan bahwa aktivitas belajar siswa mempengaruhi prestasi belajar pada mata pelajaran Kimia, siswa yang memiliki aktivitas belajar tinggi lebih baik dari siswa yang memiliki aktivitas belajar rendah. Hal ini sejalan dengan penelitian dari Wasanowati \& Redjeki (2014) yang menyatakan bahwa aktivitas belajar tinggi maka dapat meningkatkan efektifitas belajar siswa. efektifitas belajar akan emmbuat siswa mendapatkan pengetahuan yang lebih banyak dari berbagai sumber. Dimyati \& Mujiono (2009) juga berpendapat bahwa siswa yang melakukan aktivitas tinggi maka menumbuhkan rasa ingin tahu yang besar untuk mempelajari apa yang menjadi tugasnya. Dari semua hasil yang diperoleh maka dapat dikatakan bahwa untuk mencapai prestasi yang lebih baik maka diperluka model pembelajaran yang dapat meningkatkan aktivitas belajar siswa salah satunya model PBL. Model PBL dilaksanakan dari permasalahan yang nyata dapat membuat siswa ikut berpartisipasi langsung dalam proses pembelajaran dan menggugah rasa ingin tahu siswa untuk mencari informasi sebanyak-banyaknya dari berbagai sumber mengakibatkan siswa dengan sendirinya membagun pengetahuan secara mandiri.

\section{SIMPULAN}

Berdasarkan analisis dan pembahasan uji hipotesis dapat disimpulkan bahwa (1) terdapat perbedaan pengaruh yang signifikan prestasi belajar Kimia pada kelompok dengan menggunakan model PBL dan model kooperatif tipe TPS di SMA Negeri di Grobogan. Prestasi belajar siswa pada mata pelajaran Kimia dengan model pembelajaran PBL lebih baik dari pada siswa yang menggunakan model pembelajaran TPS; (2) terdapat perbedaan pengaruh yang signifikan prestasi belajar Kimia pada kelompok siswa dengan aktivitas belajar tinggi dan kelompok siswa dengan aktivitas belajar rendah. Prestasi belajar siswa pada mata pelajaran Kimia yang memiliki aktivitas belajar tinggi lebih baik dari pada siswa yang memiliki aktivitas belajar rendah; (3) terdapat interaksi antara model pembelajaran dengan aktivitas belajar terhadap prestasi belajar Kimia. Prestasi belajar pada mata pelajaran Kimia pada kelompok model PBL dengan aktivitas belajar tinggi mempunyai nilai rerata tertinggi, sedangkan kelompok model TPS dengan aktivitas belajar rendah mempunyai nilai rerata terendah.

\section{DAFTAR PUSTAKA}

Anitah, S. (2009). Teknologi Pembelajaran. Surakarta: Yuma Pustaka.

Akcay, B. (2009). Problem Based Learning in Science Education. Journal of Turkish Science Education, 6(1), hlm. 26-36.

Arends, R. I. (1997). Classroom Instruction and Management. New York: McGrow-Hill.

Bamiro, A. O. (2015). Effects of Guided Discovery and Think-Pair-Share Strategies in Secondary School Students' Achivement in Chemistry. SAGE Journal, 5(1).

BSNP. (2007). Standar Proses untuk Satuan Pendidikan Dasar dan Menengah. Jakarta: Depdiknas.

Dahar, R. W. (1996). Teori-Teori Belajar. Jakarta: Erlangga.

Dimyati \& Mudjiono. (2009). Belajar dan Pembelajaran. Jakarta: Rineka Cipta.

Duch, B. J., Allen, D. E \& White, H. B. (2002). Problem Based Learning: Preparing Students to Succed in the 21st Century. Available at http://www.Pondnetwork.org.

Doymus, K. (2008). Teaching Chemical onding Through Jigsaw Cooperative Learning. Research in Science \& Technological Education, 26(1), hlm. 47-57. 
Graaff, D. E \& Kolmos, A. (2003). Characteristics of Problem Based Learning. Int. J. Engng Ed, 19 (5), hlm. 657-662.

Joyce, B \& Weil, M. (1980). Model of teaching. New Jersey: Prentice-Hall, Inc.

Kagan, S., \& Kagan, M. (2009). Kagan Cooperative Learning. San Clemcute, CA: Kagan Publising Available in http://www.kaganonline.com

Kelly, O. C., \& Finlayson, O. E. (2007). Provoding Solution Throught Problem Based Learning for Undergraduate 1 st Chemistry Laboratory. Chemistry Education Reseach and Practice, 8(3), hlm. 341-361.

Koc, Y., Seda, O., \& Bilge, O. (2013). Effect of Cooperative Learning Model on Science and Technology Laboratory Practices Lesson. International Journal on New Trend in Education and Their Implications, 4(4), hlm. 42-57.

Oludipe, D., \& Awakoy, J. O. (2010). Effect of Cooperative Learning Teaching Strategi On The Reduction Of Students' Anxiety For Learning Chemistry. Journal of Turkish Sctene Education, 7(5), hlm. 30-36.

Sardiman. (2008). Interaksi dan Motivasi Belajar Mengajar. Jakarta: Rajawali.

Slavin, R, E. (1995). Cooperative Learning Theory, Research, and Practice Second Editions. USA: animon \& Schusse Company.

Sugiarto, D \& Sumarsono, P. (2014). The Implementation of Think Pair Share Model to Improve Students Ability in Reading Narrative Texts. International Journal of English and Education, 3(3).

Sugiyono. (2010). Metode Penelitian Pendidikan Kuantitatif Kualitatif dan R\&D. Bandung: Alfabeta.

Suharta \& Luthan, L. A. (2013). Application of cooperative problem based learning Model to develop creativity and foster democracy, and improve student learning outcomes in chemistry in high school. Journal of education and practice.

Tsankov, N. S. (2012). Students' Motivation in The Process of Problem-Based Education in Chemistry and Environmental Sciences. Internatioanl Journal of Humanities and Social Sciences, 2(21), hlm. 155-166.

Wasonowati, R. R. (2004). Penerapan Problem Based LEARNING (PBL) pada Pelajaran HukumHukum Dasar Kimia ditinjau dari Aktivitas dan Hasil Belajar Siswa Kelas X IPA SMA N 2 Surakarta. Jurnal Pendidikan Kimia, 3(3), hlm. 66-75.

Wijaya, K \& Dwitagama, D. (2010). Mengenal Penelitian Tindakan Kelas. Jakarta: Indeks. 